\title{
The Solid-State Complex of para-Sulphonato-Calix[8]Arene Anion with Dimethylammonium Cations
}

\author{
Oksana Danylyuk $^{1}$, Florent Perret ${ }^{2}$, Anthony W. Coleman*,3 and Kinga Suwinska ${ }^{1}$ \\ ${ }^{1}$ Institute of Physical Chemistry, Polish Academy of Sciences, Kasprzaka, 44/52, PL-01 224 Warszawa, Poland, \\ ${ }^{2}$ Université de Lyon, Lyon, F-69003, France ; Université Lyon 1, ICBMS UMR CNRS 5246, LCO2, Bâtiment Raulin, 43, \\ bd du 11 novembre 1918, Villeurbanne F-69622, France and ${ }^{3}$ Institut de Biologie et Chimie des Protéines, UMR 5086, \\ CNRS, Université Lyon 1, 7 passage du Vercors, F69367 Lyon, France
}

\begin{abstract}
The solid-state structure of the complex para-sulphonato-calix[8]arene - dimethylammonium - dimethylformamide shows the para-sulphonato-calix[8]arene anion in a pleated cone conformation with the inclusion of four dimethylammonium cations and the dimethylformamide positioned exo to the macrocycle.
\end{abstract}

Key Words: Solid-state, crystal structure, calix[8]arene, para-sulphonato-calix[8]arene, inclusion complex.

\section{INTRODUCTION}

The calix[n]arenes due both to their ease of synthesis and selective chemical modification, [1] and their ability to complex with a wide range of substrates ranging from ions, [2] through small molecules, [3] to bio-active molecules, [4] and even to proteins, [5] are one of the most widely studied classes of organic host molecules [6].

Of growing interest over the last ten years has been the bioactivity of these molecules, [7] and in particular the water soluble calix[n]arenes where the greatest focus has been on the para-sulphonato-calix[n]arenas [8]. These molecules and their derivatives show strong selective binding for the amino-acids, [9] and for certain peptides, [10] more importantly they bind to proteins such as the Serum Albumins, [5] and the Prion protein [11]. In the last case the binding leads to enhanced detection of the pathogenic form of the prion, [12] responsible for such neurodegenerative diseases as Bovine Spongiform Encephalitis, Scrappie and nv-Creutzfeld Jacobs Disease in humans [13]. The amplification of the detection of the prion increases with the size of the macrocycle, thus para-sulphonato-calix[4]arenes<para-sulphonato-calix [6]arenes < para-sulphonato-calix[8]arenes.

There is thus considerable interest in the determination of the structures of the para-sulphonato-calix[n]arenes and their complexes in the solid-state.

While para-sulphonato-calix[4]arenes have been widely studied, the solid-state properties of $p$-sulphonato-calix [8]arene (C8S) have been much less exploited due to its more challenging chemistry and the inherent difficulties in obtaining single crystals and authentication using X-ray diffraction data, coupled with their higher conformational flexibility. para-Sulphonato-calix[8]arene has theoretically a much larger molecular cavity than its smaller analogs and thus has great potential for enveloping large spherical guest

*Address correspondence to this author at the Institut de Biologie et Chimie des Protéines, UMR 5086, CNRS, Université Lyon 1, 7 passage du Vercors, F69367 Lyon, France; E-mail: aw.coleman@ibcp.fr molecules such as fullerenes [14] or globular shaped metal complexes in water soluble thin films, [15] in catalysis and ion transport, $[16,17]$ or acting as a surfactant for nanoparticle stabilization, as well as its potential for protein complexation. Indeed models of certain sulphonato-calix[8] arenes show molecular diameters of $3 \mathrm{~nm}$ and above, comparable to small proteins [18].

The first structural study of para-sulphonatocalix[8]arene was reported by Raston et al. in 2005 [19]. The parasulphonato-calix[8]arene molecule adopts a "pleated loop" conformation induced by the guest, 4,4'-dipyridine- $N, N$ 'dioxide, here para-sulphonato-calix[8] arene does not possess a substantial molecular cavity and the conformation is similar to that found for para-tert-Bu-calix[8]arene, [20] and para-H-calix[8] arene [21]. In the presence of tetraphenylphosphonium and trivalent ytterbium cations, parasulphonato-calix[8]arene forms large 2D porous structure [19]. The structure is complicated, consisting of pseudo molecular capsules of C8S forming an overall layered structure where the calixarenes are in bilayer arrangement. There are two kinds of criss-crossed large channels filled with water molecules and aquated ytterbium cations forming 2D porous structure.

para-Sulphonato-calix[8]arene has been shown to form chalice-like cavity for the solid state inclusion of coordination complex tris(phenanthroline)cobalt(III) $\left(\left[\mathrm{Co}(\mathrm{phen})_{3}\right]^{3+}\right)$ in the presence of trivalent ytterbium cations [22]. The encapsulation of globular shaped $\left[\mathrm{Co}(\text { phen })_{3}\right]^{3+}$ cation results in a disruption of the calixarene hydrogen bond network associated with the phenolic moieties, and the wrapping of the flexible host around the guest Here, the conformation of the para-sulphonato-calix[8]arene is best described as a distorted version of the pleated loop conformation, with the phenolic hydrogen bond network breaking down such that a $C_{2}$ symmetrical chalice is formed that is similar to that found for a bismuth cluster complex of a $p$-tert-butylcalix[8]arene [23]. The lower rim of the chalice is 'stitched' together through the two hydrogen bonding interactions between the sulphonate group from one ring and phenolic oxygen atom 
from another ring in alternate conformation. The preorganisation requirement of the calixarene in forming the complex results in the formation of large diameter, negatively charged channels within the crystal lattice.

In the complex with bulky 1,2-cyclohexanediamine $p$ sulphonato-calix[8]arene adopts an inverted double cone conformation with two identical partial cones occupied by two guest cations. For the linear 1,4-butanediamine the host is in a conformation of almost planar macrocyclic rings with grooves occupied by elongated 1,4-butanediammonium cations. In the case of 1,4-butanediamine omplex assembles with channels are occupied by disordered methanol molecules are formed. However, perpendicular to these channels, two sets of cavities are generated. The first set of cavities represent channels of an oval geometry containing one butanediammonium cation in a folded conformation and disordered methanol molecules. The cavity walls are formed mainly of sulphonate groups and are therefore highly hydrophilic. The second set of square cavities intersects and connects the first set. The butanediammonium cations in an elongated form are located within these cavities, with the ammonium head groups pointing out of them. Calixarene molecules are held together via $\mathrm{C}-\mathrm{H} \cdots \mathrm{O}$ hydrogen bonds between methylenic bridges and sulphonate groups (distances from 3.33(4) to 3.55(3) ^) [24].

It would appear that size or/and shape of the guest has the capacity to influence the shape of the para-sulphonatocalix[8]arene cavity adopted in the solid state. The mutually induced fit in host-guest complexes between conformationally flexible para-sulphonato-calix[8] arene and photolabile cholinergic ligands has been observed in solution [25]. Both the host and the guests adapted to each other and selected the higher energy but correct geometric conformers so that the guest could fit favorably into the cavity of the host to give diotopic binding of both the aromatic ring and the cationic ammonium moiety of the guest (guest host complex Fig. 1). This system with mutually induced fit represents an original example of adaptive supramolecular biomimetic chemistry.

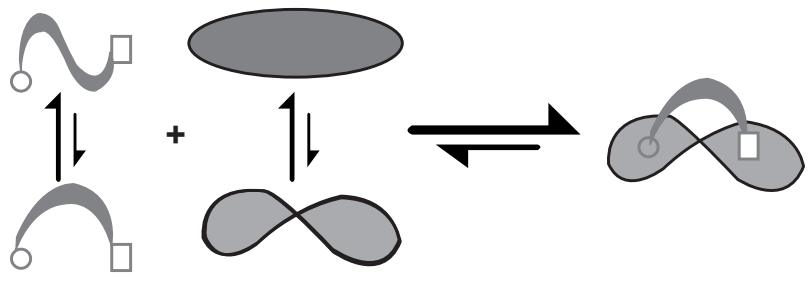

Fig. (1). Adaptive supramolecular system of para-sulphonatocalix[8]arene with flexible guest molecule.

In this paper we present the soild-state structure of parasulphonato-calix[8]arene with dimethylammonium cations.

\section{RESULTS AND DISCUSSION}

The crystallographic data for the complex of parasulphonato-calix[8]arene with dimethylammonium cations, derived from breakdown of dimimethylformaide used as the crystallization solvent, are presented in Table 1. The asymmetric unit consists of half of the para-sulphonatocalix[8]arene molecule in the form of an anion carrying four negative charges, four dimethylammonium cations named as $\mathbf{X}, \mathbf{Y}, \mathbf{Z}$ and $\mathbf{W}$, and one DMF molecule (Fig. 2).

Table 1. Crystal Data and Structure Refinement for ParaSulphonato-Calix[8]arene - Dimethylammonium Dimethylformamide Complex [26, 27]

\begin{tabular}{|c|c|c|}
\hline Molecular Formula & \multicolumn{2}{|c|}{$\left(\mathrm{C}_{56} \mathrm{H}_{40} \mathrm{O}_{32} \mathrm{~S}_{8}\right) \cdot\left(\mathrm{C}_{2} \mathrm{H}_{8} \mathrm{~N}\right)_{8} \cdot\left(\mathrm{C}_{3} \mathrm{H}_{7} \mathrm{ON}\right)_{2}$} \\
\hline Formula weight & \multicolumn{2}{|l|}{998.15} \\
\hline Temperature & \multicolumn{2}{|l|}{$100(2) \mathrm{K}$} \\
\hline Wavelength & \multicolumn{2}{|l|}{$0.71073 \AA$} \\
\hline Crystal system & \multicolumn{2}{|l|}{ Triclinic } \\
\hline Space group & \multicolumn{2}{|l|}{$\mathrm{P} 1$} \\
\hline Unit cell dimensions & $\begin{array}{l}\mathrm{a}=11.508(1) \AA \\
\mathrm{b}=12.816(1) \AA \\
\mathrm{c}=17.421(2) \AA .\end{array}$ & $\begin{array}{l}\alpha=74.999(7)^{\circ} \\
\beta=89.037(6)^{\circ} \\
\gamma=67.018(6)^{\circ}\end{array}$ \\
\hline Volume & \multicolumn{2}{|l|}{$2274.5(4) \AA^{3}$} \\
\hline $\mathrm{Z}$ & \multicolumn{2}{|l|}{1} \\
\hline Density (calculated) & \multicolumn{2}{|l|}{$1.457 \mathrm{Mg} \cdot \mathrm{m}^{-3}$} \\
\hline Absorption coefficient & \multicolumn{2}{|l|}{$0.287 \mathrm{~mm}^{-1}$} \\
\hline $\mathrm{F}(000)$ & \multicolumn{2}{|l|}{1056} \\
\hline Crystal size & \multicolumn{2}{|c|}{$0.20 \times 0.20 \times 0.10 \mathrm{~mm}^{3}$} \\
\hline$\theta$ range for data collection & \multicolumn{2}{|l|}{2.60 to $20.81^{\circ}$} \\
\hline Index ranges & \multicolumn{2}{|c|}{$-11 \leq \mathrm{h} \leq 11,-12 \leq \mathrm{k} \leq 12,-17 \leq 1 \leq 17$} \\
\hline Reflections collected & \multicolumn{2}{|l|}{9241} \\
\hline Independent reflections & \multicolumn{2}{|c|}{$4723\left[\mathrm{R}_{\mathrm{int}}=0.113\right]$} \\
\hline Completeness to $\theta=20.81^{\circ}$ & \multicolumn{2}{|l|}{$99.2 \%$} \\
\hline Absorption correction & \multicolumn{2}{|l|}{ None } \\
\hline efinement method & \multicolumn{2}{|c|}{ Full-matrix least-squares on $\mathrm{F}^{2}$} \\
\hline Data / restraints / parameters & \multicolumn{2}{|l|}{4723 / $0 / 599$} \\
\hline Goodness-of-fit on $\mathrm{F}^{2}$ & \multicolumn{2}{|l|}{0.93} \\
\hline Final $\mathrm{R}$ indices $[\mathrm{I}>2 \sigma(\mathrm{I})]$ & \multicolumn{2}{|c|}{$\mathrm{R}=0.062, \mathrm{wR}=0.103$} \\
\hline $\mathrm{R}$ indices (all data) & \multicolumn{2}{|c|}{$\mathrm{R}=0.129, \mathrm{wR}=0.118$} \\
\hline Extinction coefficient & \multicolumn{2}{|l|}{$0.0024(5)$} \\
\hline Largest diff. peak and hole & \multicolumn{2}{|c|}{0.26 and $-0.30 \mathrm{e} \cdot \AA^{-3}$} \\
\hline
\end{tabular}

para-Sulphonato-calix[8]arene adopts a conformation (Fig. 3) in which three of the phenolic rings point up from the mean plane of the molecule, three point down and the other two phenolic rings are self-included in the macrocyclic cavity forming intramolecular hydrogen bonds between phenolic oxygen atoms acting as donors and sulphonate oxygen atoms acting as acceptors with the distance of 2.855(6) $\AA$. In this conformation the typical hydrogen bonding between vicinal hydroxyl groups does not exist. 
This centrosymmetric para-sulphonato-calix[8]arene conformation provides two pairs of identical binding sites for two dimethylammonium cations, $\mathbf{W}$ and two other dimethylammonium cations, $\mathbf{Y}$ leading to 1:4 host-guest inclusion stoichiometry (Fig. 4).

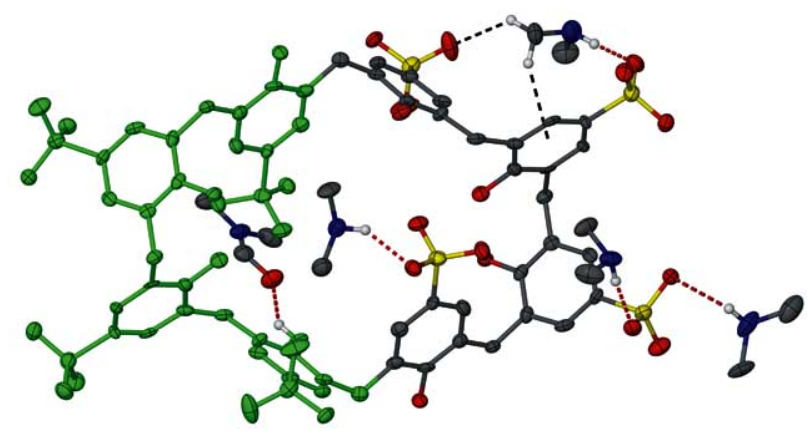

Fig. (2). Asymmetric unit of the para-sulphonato-calix[8]arene complex with dimethylammonium (symmetry-generated atoms in green).

Hydrogen bonding data is given in Table 2. Cations $\mathbf{Y}$ are located in the identical grooves formed by two phenolic rings pointing up and two phenolic rings pointing down and form hydrogen bond between ammonium nitrogen atom and sulphonate oxygen atom of the host with the distance of 2.820(7) $\AA$. Cations $\mathbf{W}$ are situated between two included phenolic rings on each side of the macrocycle and form hydrogen bonds to the oxygen atoms of two sulphonate groups of 2.780(7) and 2.847(7) $\AA$. The complexation is additionally stabilized by $\mathrm{C}-\mathrm{H} \cdots \mathrm{O}$ hydrogen bond (3.446(9) $\AA$ ) between methyl carbon atom of the cation $\mathbf{W}$ and one of the phenolic oxygen atom of the host.

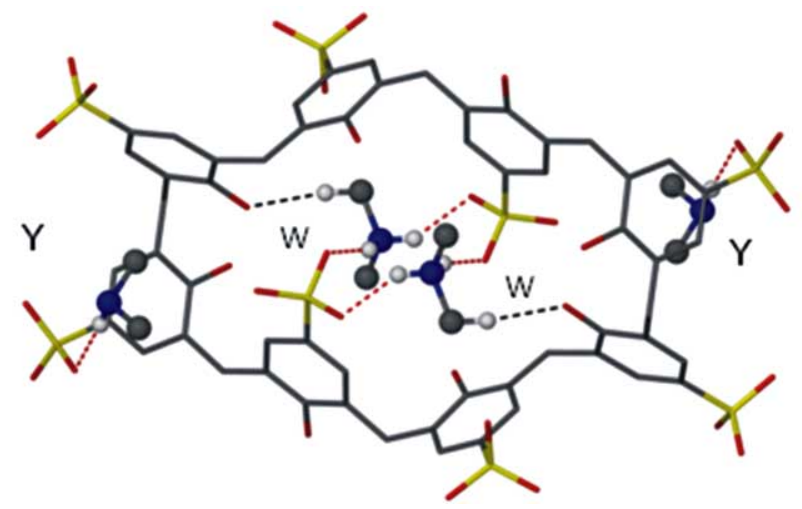

Fig. (4). Inclusion complex of para-sulphonatocalix[8]arene with dimethylammonium cations.

The cations $\mathbf{X}$ and $\mathbf{Z}$ are complexed between the neighboring para-sulphonato-calix [8]arene molecules by $\mathrm{N}-\mathrm{H} \cdots \mathrm{O}$ hydrogen bonding. Both cations form one bifurcated hydrogen bond with two sulphonate oxygen atoms and one normal hydrogen bond also with sulphonate oxygen atom. The network of hydrogen bonds generated by all four crystallographically independent dimethylammonium cations is presented in Fig. (5).

As shown in Fig. (6), the overall structure reveals the layered character of the packing. There are no distinct hydrophobic and hydrophilic layers in the structure. The struc-

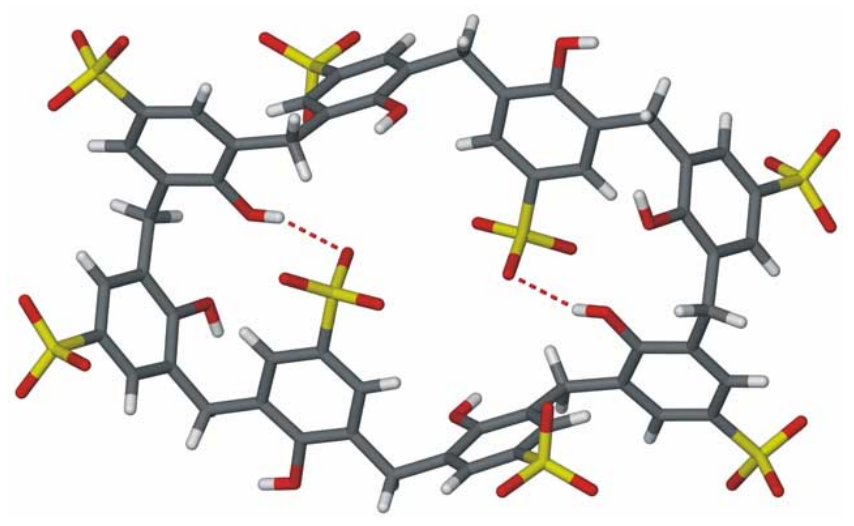

(b)

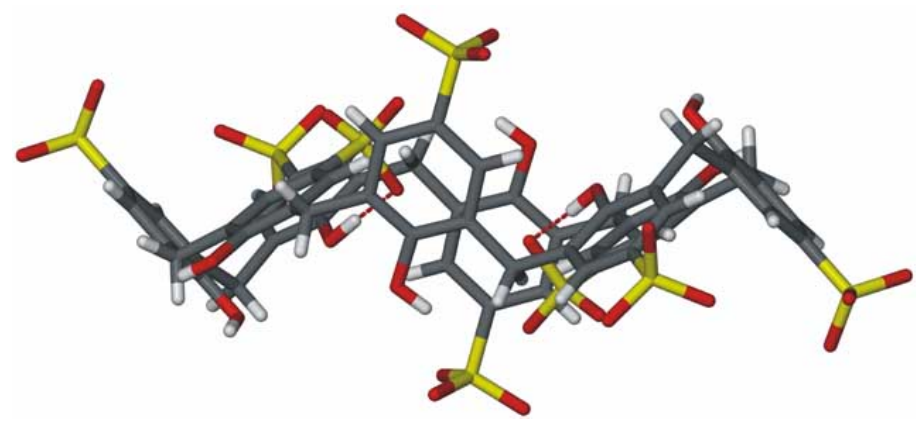

Fig. (3). para-Sulphonato-calix[8]arene conformation in the dimethylammonium complex: (a) top view; (b) side view. 
Table 2. Hydrogen Bonding Data for Para-Sulphonato-Calix[8]Arene - Dimethylammonium Complex $\left(\AA^{\mathrm{A}}\right.$ and $\left.{ }^{\circ}\right)$

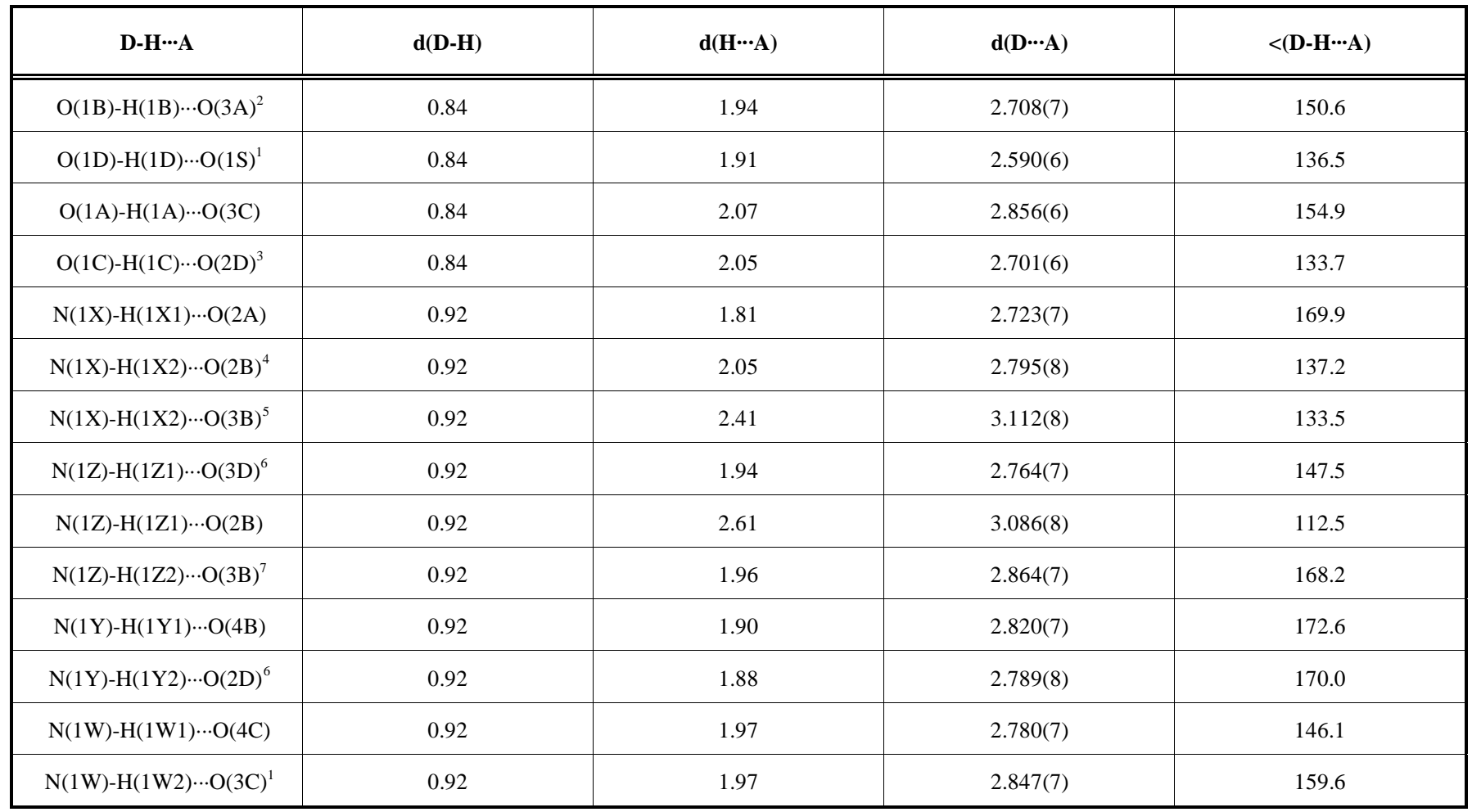

(1) -x,-y,-z-1; (2) $\mathrm{x}-1, \mathrm{y}, \mathrm{z}$; (3) $\mathrm{x}-1, \mathrm{y}+1, \mathrm{z}$; (4) -x+1,-y,-z; (5) $\mathrm{x}+1, \mathrm{y}-1, \mathrm{z} ;(6) \mathrm{x}, \mathrm{y}+1, \mathrm{z} ;$ (7) -x,-y+1,-z.

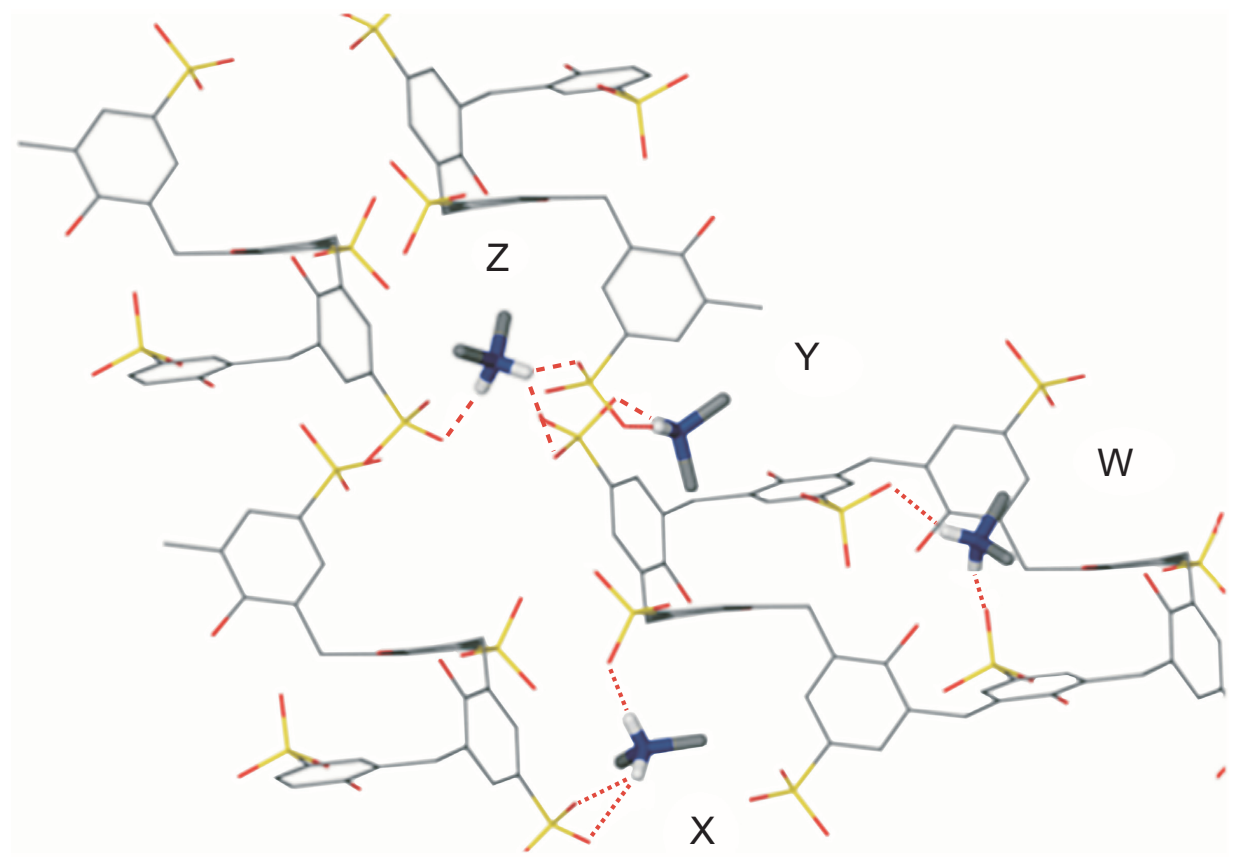

Fig. (5). Hydrogen bonding generated by the four independent dimethylammonium cations.

ture is stabilised by a number of $\mathrm{C}-\mathrm{H} \cdots \pi$ interactions, given in Table 3.

\section{CONCLUSION}

In the complex with the small dimethylammonium cations para-sulphonato-calix[8]arene adopts an intermedi- ate conformation between the double inverted cone and the almost planar macrocyclic ring with three of the phenolic rings pointing up from the mean plane of the molecule, three pointing down and the other two of the phenolic rings being self-included in the macrocyclic cavity. In this conformation typical hydrogen bonding between neighboring phenolic 


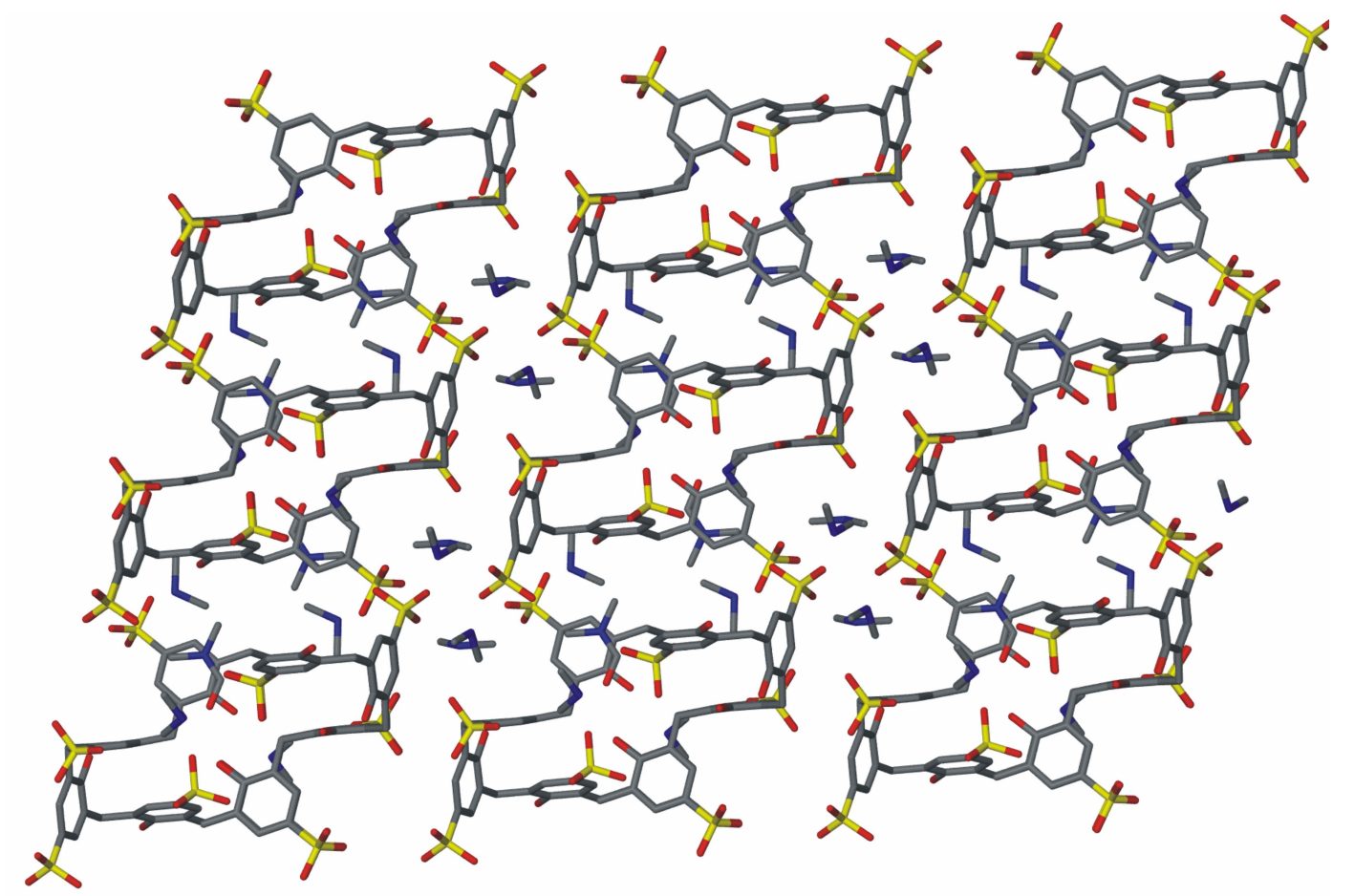

Fig. (6). Molecular packing of the para-sulphonato-calix[8]arene-dimethylammonium complex alongthe $a$ axis.

Table 3. C-H $\cdots \pi$ Interactions for Para-Sulphonato-Calix[8]Arene - Dimethylammonium $\left(\AA\right.$ and $\left.{ }^{\circ}\right)$, where $\mathrm{Cg} 1, \mathrm{Cg} 2$ and $\mathrm{Cg3}$ are the Centroids of the Benzene Rings (C1A-C6A), (C1B-C6B) and (C1C-C6C), Respectivly

\begin{tabular}{|c|c|c|c|c|}
\hline $\mathbf{C}-\mathbf{H} \cdots \boldsymbol{\pi}$ & $\mathbf{d}(\mathbf{C}-\mathbf{H})$ & $\mathbf{d}(\mathbf{H} \cdots \mathbf{C g})$ & $\mathbf{d}(\mathbf{C} \cdots \mathbf{C g})$ & $<(\mathbf{C}-\mathbf{H} \cdots \mathbf{C g})$ \\
\hline \hline $\mathrm{C} 3 \mathrm{~S}-\mathrm{H} 3 \mathrm{~S} 3 \cdots \mathrm{Cg} 1^{\mathrm{i}}$ & 0.98 & 2.96 & $3.415(9)$ & 110 \\
\hline $\mathrm{C} 2 \mathrm{X}-\mathrm{H} 2 \mathrm{X} 1 \cdots \mathrm{Cg} 2$ & 0.98 & 2.87 & $3.760(8)$ & 152 \\
\hline $\mathrm{C} 1 \mathrm{Z}-\mathrm{H} 1 \mathrm{Z} 3 \cdots \mathrm{Cg} 3^{\mathrm{ii}}$ & 0.98 & 2.83 & $3.722(9)$ & 151 \\
\hline
\end{tabular}

(i) $-1+x, y, z$; (ii) $-x, 1-y,-z$.

rings does not exist. In this complex para-sulphonatocalix[8]arene complex host includes dimethyammonium cations, while dimethylformaide molecules are complexed exo to the cavity.

\section{REFERENCES}

[1] Asfari Z, Bohmer V, Harrowfield J, Vicens J, and Saadioui M. eds Calixarenes 2001. Kluwer: Dordrecht, 2001.

[2] Atwood J L, Barbour L J, Hardie M J, and Raston C L. Metal sulfonatocalix $[4,5]$ arene complexes: bi-layers, capsules, spheres, tubular arrays and beyond. Coord Chem Rev 2001; 222: 3-32.

[3] Nichols J, Makha M, Raston C L. Confinement of Nucleic Acid Bases and Related Compounds Using Tetra-p-sulfonatocalix[4] arene. Cryst Growth Des 2006; 6: 1161-67.

[4] Coleman A W, Lazar A N, Da Silva E, Calixarenes and Their Analogues: Cation Complexation. in Encyclopedia of Macromolecular Science. Taylor \& Francis Ltd: New York, 2004.

[5] Da Silva E, Rousseau C F, Zanella-Cleon I, Becchi M, and Coleman A W. Mass Spectrometric Determination of Association Constants of Bovine Serum Albumin (BSA) with para-SulphonatoCalix[n]arene Derivatives, J Incl Phenom Macrocycl Chem 2006; 55: 53-9; Memmi L, Lazar A N, Brioude A, Ball V, and Coleman A W. Protein-calixarene interactions: complexation of Bovine Serum Albumin by sulfonatocalix[n]arenes. Chem Commun 2001; 24742475.

[6] Gutsche C D. Calix-arenes: an Introduction, $2^{\text {nd }}$ Edition, RSC: Cambridge, 2008
[7] Da Silva E, Lazar A N, and Coleman AW. Biopharmaceutical applications of calixarenes. J Drug Del Sci Tech 2004; 14: 3-20.

[8] Perret F, Lazar A N, Coleman A W. Biochemistry of the parasulfonato-calix[n]arenes. Chem Commun 2006; 2425-2438.

[9] Kalchenko O I, Da Silva E, and Coleman A W. Determination of the Stability Constants of Inclusion Complexes of p-H-37-(2carboxy-methyloxy)-calix-[6]-arene and p-sulphonato-37-(2-carboxy-methyloxy)-calix-[6]-arene with 15 Amino acids by RPHPLC. J Incl Phenom Macrocycl Chem 2002; 43: 305-310; Da Silva E and Coleman A W. Synthesis and complexation properties towards amino acids of mono-substituted p-sulphonato-calix-[n]arenes. Tetrahedron 2003; 59: 7357-7364. Douteau-Guevel N, Coleman A W, Morel J-P, Morel-Desrosiers N. Complexation of the basic amino acids lysine and arginine by three sulfonatocalix[n]arenes $(\mathrm{n}=4,6$ and 8$)$ in water: microcalorimetric determination of the Gibbs energies, enthalpies and entropies of complexation. J C S Perkin Trans 2 1999; 629-634.

[10] Douteau-Guevel N, Perret F, Coleman A W, Morel J-P, and MorelDesrosiers N. Binding of dipeptides and tripeptides containing lysine or arginine by p-sulfonatocalixarenes in water: NMR and microcalorimetric studies. J C S Perkin Trans 2 2002; 524-532.

[11] Coleman A W, Perret F, Cecillon S, et al. Enhanced Detection of the Pathogenic Prion Protein by its Supramolecular Association with para-Sulphonato-Calix[n]arene Derivatives. New J Chem 2007; 31: 711-717.

[12] Perret F, Peron H, Dupin M and Coleman A W. Calix-arenes as Protein Sensors. Topics in Current Chem Creative Chemical Sensor Systems, ed T. Schrader 2007; 277: 31-88, Springer, Berlin 
[13] Pruniser S B. Prion Biology and Disease $2^{\text {nd }}$ Edition, Cold Spring Harbour Laboratory Press, Cold Spring Harbour, USA, 2004.

[14] Hatano T, Bae A-H, Sugiyasu K, et al. A latent photoreaction predominates within water-soluble calixarenes: photochemistry of benzoin alkyl ethers. Org Biomol Chem 2003; 1: 2343- 7.

[15] Li C, Hatano T, Takeuchi M, and Shinkai S. Tetrahedron 2004; 60: 8037.

[16] Kaliappan R, Kaanumalle L S and Ramamurthy V. A latent photoreaction predominates within water-soluble calixarenes: photochemistry of benzoin alkyl ethers. Chem Commun 2005; 4056- 58.

[17] Goto K, Yano Y, Okada E, Liu C-W, Yamamoto K and Ueoka R. Catalytic Specificity Exhibited by $p$-Sulfonatocalix $[n]$ arenes in the Methanolysis of $N$-Acetyl-L-amino Acids. J Org Chem 2003; 68: 865-70.

[18] Jebors S, Fache F, Balme S, et al. Designer amphiphiles based on para-acyl-calix[8]arenes. Org Biomol Chem 2008; 6: 319-329.

[19] Dalgarno S J, Hardie M J, Atwood J L, Warren J E and Raston C L. A complex 3D 'wavy brick wall' coordination polymer based on psulfonatocalix [8]arene. New J Chem 2005; 29: 649-52.

[20] Czugler M, Tisza S and Speier G. Versatility in inclusion hosts: unusual conformation in the crystal structure of the p-tertbutylcalix [8]arene: pyridine (1:8) clathrate. J Incl Phenom Macrocycl Chem 1991; 11:323-31.
[21] Bergougnant P D, Robin A Y, Fromm K M. Hooked-on Calix [8] arenes : A $\left(\mathrm{H}_{2} \mathrm{O}\right) 10$ Cluster with an Unprecedented Structure. Crystal Growth Des 2005; 5: 1691-1694.

[22] Makha M, Sobolev A N and Raston C L. Constructing 2D porous material based on the assembly of large organic ions: $\mathrm{p}$ sulfonatocalix [8]arene and tetraphenylphosphonium ions. Chem Commun 2006; 511-13.

[23] Smith C B, Barbour L J, Makha M, Raston C L and Sobolev A N. Unlocking the elusive binding cavity in p-sulfonatocalix[8]arene. New J Chem 2006; 30: 991-6.

[24] Perret F, Bonnard V, Danylyuk O, Suwinska K and Coleman A W. Conformational extremes in the supramolecular assemblies of parasulfonato-calix [8]arene. New J Chem 2006; 30: 987-90.

[25] Specht A, Bernard P, Goeldner M and Peng L. Mutually induced formation of host-guest complexes between p-sulfonated calix[8]arene and photolabile cholinergic ligands. Angew Chem Int Ed 2002; 41: 4706-8

[26] Sheldrick G M. Phase annealing in SHELX-90: direct methods for larger structures. Acta Cryst 1990; A46: 467-473.

[27] Sheldrick G M. SHELX97. Programs for Crystal Structure Analysis (Release 97-2).1997, University of Göttingen, Germany.

(C) Danylyuk et al.; Licensee Bentham Open.

This is an open access article distributed under the terms of the Creative Commons Attribution License (http://creativecommons.org/licenses/by/2.5/), which permits unrestrictive use, distribution, and reproduction in any medium, provided the original work is properly cited. 